\title{
Recurrent pretibial edema associated with zuclopenthixol acetate: $A$ case report
}

\author{
Ekin Dagistan ${ }^{1}$, Berkay Vahapoglu $^{2}$ \\ 'Bakirkoy Training and Research Hospital for Psychiatry, Neurology and Neurosurgery, Department of Psychiatry, Istanbul - Turkey \\ ${ }^{2}$ Devrek State Hospital, Department of Psychiatry, Zonguldak - Turkey
}

\begin{abstract}
Zuclopenthixol acetate is an injectable depot antipsychotic that is effective for 24-48 hours and mainly used for the treatment of acute mania or psychotic episodes. To our knowledge, there is only one case report reporting edema after zuclopenthixol use, which described a patient had suffered from facial and peripheral edema after zuclopenthixol decanoate injection. Here, we present a patient with bipolar disorder who developed bilateral pretibial edema following repeated zuclopenthixol acetate injections. A 53-year-old male patient with no previous medical history presented with manic symptoms. Based on his past psychiatric treatment history, zuclopenthixol acetate was initiated, and three positive pretibial edema developed bilaterally after administration. Although no pathological findings to explain edema were detected, the Naranjo Adverse Reaction Probability Scale showed a "probable" relationship of zuclopenthixol and edema with a score of 8. Peripheral edema may develop due to various common medical conditions including antipsychotic drugs and can be life-threatening. Although the exact mechanisms of peripheral edema due to antipsychotic use are still unknown, further studies may shed further light on these mechanisms.
\end{abstract}

Keywords: Adverse effect, antipsychotics, bipolar disorder, edema, zuclopenthixol

\section{INTRODUCTION}

Zuclopenthixol acetate is an injectable depot antipsychotic that is effective for 24-48 hours, mostly used in the treatment of acute mania or psychotic agitation, due to its early sedative effect and low side effect risk (1). However, repeated injections are often required as a result of their short-term therapeutic effects. Its mechanism of action is believed to include 5-HT2A, D1, D2, and alpha-1 adrenergic receptor antagonisms. The most common side effects reported include drowsiness and extrapyramidal side effects such as acute akathisia (2). Edema induced by antipsychotics is rarely reported, and the case reports mostly highlight atypical antipsychotics (3). To our knowledge, there is only one case report including a patient with facial and peripheral edema after zuclopenthixol decanoate injection, describing edema after use of zuclopenthixol (4). Here, we present a patient with bipolar disorder who developed bilateral pretibial edema following repeated zuclopenthixol acetate injections. The patient was informed and a written consent form was obtained before writing the case report.

How to cite this article: Dagistan E, Vahapoglu B. Recurrent pretibial edema associated with zuclopenthixol acetate: A case report. Dusunen Adam The Journal of Psychiatry and Neurological Sciences 2021;34:212-215.

Correspondence: Ekin Dagistan, Bakirkoy Training and Research Hospital for Psychiatry, Neurology and Neurosurgery, Department of Psychiatry, Istanbul - Turkey

E-mail: edagistan@gmail.com

Received: December 27, 2020; Revised: January 04, 2021; Accepted: April 06, 2021 


\section{CASE}

A 53-year-old male bipolar disorder patient with no history of illegal substance use or alcohol consumption presented with reduced sleep, increased energy, excessive spending, and inflated self-esteem that had started four days ago. His treatment was valproic acid (VPA) $1750 \mathrm{mg}$, quetiapine $200 \mathrm{mg}$, biperiden $2 \mathrm{mg}$, and paliperidone $6 \mathrm{mg}$ daily. Psychiatric examination showed elevated mood, euphoria, increased speed, and content of speech, with no psychotic symptoms. The patient has suffered from bipolar disorder for more than 30 years and his history mainly includes seasonalpatterned manic episodes. His episodes were under control with treatment options such as lithium, risperidone, or haloperidol, however, lithium was discontinued due to the thyroid enzyme dysregulation and replaced with VPA five years ago. Over the years, it was thought that the antipsychotics he used also elicited and worsen subclinical depressive symptoms in the euthymic phases. This led to a change in olanzapine, but due to the elevation in his liver enzymes, it was discontinued. His antipsychotic treatment was switched to amisulpride and he had been receiving amisulpride for the last four years. Additionally, his manic episodes responded rapidly to repeated injections of zuclopenthixol acetate, nevertheless, a 1-month depot injection of zuclopenthixol was not added to his remission treatment due to its potential depressive effect on mood because of its typical antipsychotic mechanism. A year ago, he had redeveloped a manic episode which was linked to the seasonality while being treated with VPA $1750 \mathrm{mg}$, quetiapine $600 \mathrm{mg}$, biperiden $2 \mathrm{mg}$, and amisulpride $800 \mathrm{mg}$ daily. Four doses of zuclopenthixol acetate with 3-day intervals were commenced at that time, and $2+$ pretibial edema had developed in both legs five days after the treatment. Vital signs, echocardiography (ECG), kidney and liver function tests, electrolytes, thyroid function tests, serum proteins, cardiac markers, C-reactive protein, and erythrocyte sedimentation rate showed no pathological findings except elevated fasting blood glucose (155 $\mathrm{mg} / \mathrm{dL})$ and creatine kinase (CK) (380 U/L). Pretibial edema had resolved without treatment in 1 month. No treatment changes were made in the past year, except the switch from amisulpride to paliperidone due to the unavailability of amisulpride in the market.

Based on his past psychiatric treatment history, zuclopenthixol acetate was reintroduced. Injections were repeated four times at a 3-day interval due to his therapy-resistant symptoms. Initially, he developed $1+$ pretibial edema in the right leg after the $2^{\text {nd }}$ injection. Elevated CK (450 U/L), elevated blood glucose (174 $\mathrm{mg} / \mathrm{dLl}$ ), elevated gamma-glutamyl transferase (GGT) (59 U/L), and mild hyponatremia $(133 \mathrm{mmol} / \mathrm{L})$ were detected in his blood tests. Kidney and liver function tests, electrolytes, thyroid function tests and vital signs were within the normal limit. The heart rate was 82 bpm in his ECG, and the QT interval was calculated as 423 milliseconds. The $3^{\text {rd }}$ injection was readministered three days later, and no change in the severity of edema was observed. However, bilateral $3+$ pretibial edema developed after the $4^{\text {th }}$ injection. Repeated blood tests and re-evaluated vital signs found no significant changes. ECG and examination were performed by the cardiology department, which showed no pathological findings with normal ejection fraction (60\%). Furosemide $40 \mathrm{mg} /$ day was added and the edema gradually resolved 40 days after the last injection. The Naranjo Adverse Reaction Probability Scale (NARPS) showed a "probable" relationship between zuclopenthixol and edema with a score of 8 (5). His final medications included VPA $2000 \mathrm{mg}$, quetiapine $400 \mathrm{mg}$, biperiden $2 \mathrm{mg}$, paliperidone $9 \mathrm{mg}$ and furosemide $40 \mathrm{mg}$ daily.

\section{DISCUSSION}

In this patient, zuclopenthixol acetate was considered an option due to its noticeable benefit during his previous manic episodes.

Peripheral edema may develop due to various common medical conditions, including cardiovascular disorders, renal dysfunction, thyroid dysfunction, and liver diseases (6). However, our patient's medical history, physical examinations and laboratory tests did not reveal an underlying pathology for the cause of edema. Urological, hepatic or endocrine metabolism pathologies were also particularly excluded by the same methods.

Medications can also cause peripheral edema. In the literature review of peripheral edema associated with antipsychotic treatment, the most common edema region was the legs (7). Risperidone, olanzapine and quetiapine are among the drugs most commonly and equally associated with this effect (7). Again, edema is most common in the first four weeks of treatment, and resolves within an average of 10.3 days after adjustment of treatment (7). In an another review evaluating both typical and atypical antipsychotics, risperidone, olanzapine, and quetiapine were shown to 
be the most common culprits for edema (8). In this study, haloperidol and chlorpromazine were also found to be associated with peripheral edema, although it was relatively rare compared to atypical antipsychotics (8).

Several mechanisms related to edema associated with antipsychotics have been proposed. The first mechanism involves a direct antidopaminergic effect on the dopaminergic neurons of the renal tubules, leading to alterations in the renin/aldosterone system, inhibition of renal sodium excretion, leading to fluid retention (9).

The second proposed mechanism involves $\alpha-1$ and 5HT-2 receptor antagonism due to antipsychotics, leading to peripheral vascular dilation and reduced peripheral resistance $(10,11)$. Finally, allergic reactions were held responsible for the mechanism. In a case report of risperidone-associated edema, risperidone was thought to reduce the already low $\mathrm{C} 1$ levels and to cause C4-C2 activation, leading to angioedema (12).

Zuchlopenthixol's main action mechanism includes D1 and D2 receptor antagonisms. It also has a high affinity for alpha-adrenergic and 5-HT2 receptors and a weak histamine $\mathrm{H} 1$ receptor blocking mechanism (13). Considering the mechanisms suggested for edema caused by the use of other antipsychotics and the zuclopenthixol receptor profile together, the $\alpha-2$ adrenergic antagonism of zuclopenthixol and weak histamine $\mathrm{H} 1$ receptor blockage can be held responsible for the patient's pretibial edema.

Cardiac side effects due to the use of multiple antipsychotics are also known to be associated with peripheral edema (14). However, in the cardiological examination of our patient, no finding suggesting an underlying cardiac pathology was revealed. the actual cause of the pretibial edema was the use of zuclopenthixol acetate in the absence of a severe physical disease, the repeated pattern of the adverse effect, the long-term and stable use of other medications and the complete resolution of the edema 1 month after the discontinuation of injections were considered. Additionally, the patient's NARPS score was 8, indicating a "probable" relationship (5).

Several treatment strategies have been described for the edema induced by antipsychotics. Although peripheral edema is rare, it can even lead to discontinuation of antipsychotics when it's severe (15). Edema resolved in one gatient by reducing the dose of the antipsychotic (7). In other cases, the edemainducing antipsychotics were switched $(16,17)$. In our patient, zuclopenthixol acetate was discontinued after the remission, and $3+$ edema occurred, while furosemide was initiated at the same time. There are case reports also indicating that the furosemide use might be beneficial for edema treatment $(18,19)$. Additionally, zuclopenthixol decanoate injections were found disadvantageous due to the risk of severe druginduced edema and subclinical depressive symptoms during his euthymic phases.

Although the exact mechanisms of antipsychoticinduced edema are unknown, further studies examining other risk factors such as antipsychotic doses or comorbidity may shed more light on these mechanisms.

\begin{tabular}{|c|c|c|}
\hline \multicolumn{2}{|c|}{ Contribution Categories } & \multirow{2}{*}{$\begin{array}{l}\text { Author Initials } \\
\text { E.D. }\end{array}$} \\
\hline \multirow{4}{*}{ Category 1} & Concept/Design & \\
\hline & Literature review & E.D., B.V. \\
\hline & Data analysis/Interpretation & E.D. \\
\hline & Case follow-up (if applicable) & E.D., B.V. \\
\hline \multirow{2}{*}{ Category 2} & Drafting manuscript & E.D., B.V. \\
\hline & Critical revision of manuscript & E.D. \\
\hline Category 3 & Final approval and accountability & E.D. \\
\hline \multirow{2}{*}{ Other } & Technical or material support & E.D. \\
\hline & Supervision & E.D. \\
\hline
\end{tabular}

Acknowledgments: The authors are grateful to the patient and his family for their consent and permission for their medical condition to be published.

Informed Consent: A written informed consent form was obtained from the patient.

Peer-review: Externally peer-reviewed.

Conflict of Interest: No conflict of interest.

Financial Disclosure: No financial disclosure.

\section{REFERENCES}

1. Fenton M, Coutinho ES, Campbell C. Zuclopenthixol acetate in the treatment of acute schizophrenia and similar serious mental illnesses. Cochrane Database Syst Rev 2001; 3:CD000525. [CrossRef]

2. Barnes CW, Alderton D, Castle D. The development of clinical guidelines for the use of zuclopenthixol acetate. Australas Psychiatry 2002; 10:54-58. [CrossRef]

3. Orum MH. Antipsychotic drugs and peripheral edema: A review. Med Records 2020; 2:39-43. [Turkish] [CrossRef]

4. Orum M, Kara M. Facial and Peripheral Edema Associated with Zuclopenthixol Decanoate Longacting Injectable: A case report. Med J West Black Sea 2019; 3:26-29.[CrossRef]

5. Naranjo CA, Busto U, Sellers EM, Sandor P, Ruiz I, Roberts EA, et al. A method for estimating the probability of adverse drug reactions. Clin Pharmacol Ther 1981; 30:239-245. [CrossRef] 
6. Cho S, Atwood JE. Peripheral edema. Am J Med 2002; 113:580586. [CrossRef]

7. Umar MU, Abdullahi AT. Self-limiting Atypical Antipsychoticsinduced Edema: Clinical Cases and Systematic Review. Indian J Psychol Med 2016; 38:182-188.[CrossRef]

8. Chen HJ, Lin ST, Hsu HC, Cheng KD, Tsang HY. Paliperidonerelated peripheral edema: a case report and review of the literature. J Clin Psychopharmacol 2014; 34:269-271. [CrossRef]

9. Witz L, Shapiro MS, Shenkman L. Chlorpromazine induced fluid retention masquerading as idiopathic oedema. Br Med J (Clin Res Ed) 1987; 294:807-808. [CrossRef]

10. Tamam L, Ozpoyraz N, Unal M. Oedema associated with risperidone: a case report and literature review. Clin Drug Investig 2002; 22:411-414. [CrossRef]

11. Ng B, Postlethwaite A, Rollnik J. Peripheral oedema in patients taking olanzapine. Int Clin Psychopharmacol 2003; 18:57-59.

12. Talaei A, Faraji Rad S, Borhani Moghani M, Talaei A. Acquired angioedema induced by risperidone. Iran J Psychiatry Behav Sci 2018; 12:e4807.
13. Javed Q, Chorghade A, Javed S, Pervez Y. Reduction in selfharming behaviour after zuclopenthixol decanoate. Prog Neurol Psychiatry 2014; 18:23-27. [CrossRef]

14. Mackin P. Cardiac side effects of psychiatric drugs. Hum Psychopharmacol 2008; 23(Suppl.1):3-14.[CrossRef]

15. Koleva HK, Erickson MA, Vanderlip ER, Tansey J, Mac J, Fiedorowicz JG. 3 case reports of edema associated with quetiapine. Ann Clin Psychiatry 2009; 21:77-80.

16. Nayak V, Chogtu B, Devaramane V, Bhandary PV. Pedal edema with olanzepine. Indian J Pharmacol 2009; 41:49-50. [CrossRef]

17. Akin S, Bahat G, Tufan F, Saka B, Oztop N, Erten N, et al. Olanzapine as a cause of peripheric edema in an elderly man. Aging Clin Exp Res 2013; 25:115-117. [CrossRef]

18. Munshi S, Mukherjee S, Saha I, Sen S. Pedal edema associated with atypical antipsychotics. Indian J Pharmacol 2016; 48:8890. [CrossRef]

19. Ku HL, Su TP, Chou YH. Ziprasidone-associated pedal edema in the treatment of schizophrenia. Prog Neuropsychopharmacol Biol Psychiatry 2006; 30:963-964. [CrossRef] 